\title{
O ERUDITO E O POPULAR EM SARGENTO GETÚLIO
}

\author{
Letícia Dutra*
}

\begin{abstract}
RESUMO: A tradição literária e o cânone brasileiros ainda não cederam um espaço significativo para as formas consideradas "impuras", tais quais a cultura popular e a literatura oral. Sendo assim, o presente ensaio pretende apresentar alguns aspectos dessas produções, discutir o regionalismo brasileiro e as manifestações desses elementos nos diferentes períodos da história regionalista e, enfim, a partir da análise do romance Sargento Getúlio, de João Ubaldo Ribeiro, explorar os dados de cultura popular e de literatura oral abordados no livro, comprovando, deste modo, como duas perspectivas opostas - erudito e popular podem figurar de maneira legítima dentro de uma narrativa canônica.
\end{abstract}

PALAVRAS-CHAVE: Tradição literária - Popular - Sargento Getúlio

RESUMEN: La tradición literaria y los cánones brasileños todavía no permiten un espacio significativo a las formas consideradas “impuras", tales como la cultura popular y la literatura oral. De esta forma el presente ensayo busca presentar algunos aspectos de esas producciones, discutir el regionalismo brasileño y las manifestaciones de esos elementos en los diferentes períodos de la historia regionalista y, por fin, a partir del análisis de la novela Sargento Getúlio, de João Ubaldo Ribeiro, explorar los datos de cultura popular y de literatura oral abordados en el libro, comprobando, de este modo, como dos perspectivas opuestas erudito y popular - pueden figurar de manera legítima dentro de una narrativa canónica.

PALABRAS-CLAVE: Tradición literaria - Popular - Sargento Getúlio

\section{ABORDAGENS DO POPULAR}

O caráter heterogêneo e plural das manifestações populares não raro atrai referências negativas à cultura popular. E essa rejeição não se deve somente pela falta de sistematização dessas produções, mas, principalmente, por elas traduzirem os valores do povo, que sempre foi desprezado pelas elites - intelectual, econômica e social - e considerado como símbolo do atraso cultural.

Segundo Xidieh (apud BOSI, 2002, p. 277), um dos mais empenhados estudiosos da cultura popular brasileira, "Qualquer elaboração oral por mais que pareça simples divertimento, encerra sempre algo de utilidade, de preceito e de etiqueta". Isso acontece porque, mesmo que essas manifestações tratem de assuntos ditos superficiais, como ritos religiosos, lendas, festividades populares, elas nunca o fazem gratuitamente, pois têm a função de preservar a identidade, os costumes, as crenças e os valores, através do retorno a

\footnotetext{
* Graduada em Letras - Licenciatura em Português e Literatura de Língua Portuguesa pela UFRGS leti_dutra@hotmail.com
} 
essas situações, realizado de boca em boca, ao longo dos tempos, de geração a geração, perpetuando-se no inconsciente coletivo da população.

Percebemos, pois, que o tempo da cultura popular é cíclico, e o folclore é enraizado. A cultura das classes iletradas sobrevive à falta de registro escrito através da memória social, isto porque suas produções não se constituem somente de modos de comunicação e expressão, mas, principalmente, de práticas sociais simbólicas que determinam princípios e comportamentos.

No contexto da sabedoria popular, essas práticas, quase todas anônimas, manifestam-se na forma de cantos, adivinhas, orações, simpatias, frases feitas, lendas, mitos, estórias de lutas e de amor, etc. e funcionam como respostas aos problemas e aos anseios do povo. A esse respeito, Bosi afirma:

\footnotetext{
É que essas elaborações da literatura popular flutuam entre o real e o imaginário; projetam-se, indiferentemente, em torno de personagens humanos, animais, vegetais e do mundo inanimado; aninham-se às cronologias históricas e aos fatos comprováveis, transbordando, no entanto, para a intemporalidade e para o anacronismo (BOSI, 2002, p. 279)
}

Sendo assim, constatamos por que essas elaborações não são, de forma alguma, gratuitas, afinal elas mesclam aspectos do cotidiano das classes populares, acrescentando elementos mágicos que reforçam valores e idéias universais, mostrando que o mundo não se resume ao local onde se vive.

A falta de registros escritos formais do modo de ser e de agir das civilizações orais não impede que elas permaneçam na história, sendo lembradas e caracterizadas. Isso ocorre porque dentro do suposto caos, causado pela "impureza" dessas manifestações, observamos um traço peculiar - a resistência - que faz do povo a matéria e não a razão das produções populares, permitindo que o tempo subjetivo resista ao tempo histórico.

\section{A TRADIÇÃO LITERÁRIA BRASILEIRA E A QUESTÃO DO REGIONALISMO}

Na literatura, este termo, invariavelmente, aparece ligado ou ao tema abordado, ou à linguagem utilizada (pelo narrador ou pelas personagens). Muitas vezes, essas duas características se misturam, como veremos mais adiante.

No período romântico, o regionalismo acabou tornando-se a forma mais utilizada para manifestar nossa nacionalidade. Sobre o assunto, Antonio Candido diz que:

\footnotetext{
Teoricamente, o nacionalismo independe do Romantismo, embora tenha encontrado nele o aliado decisivo.

Podemos mesmo supor, para argumentar, formas não-românticas em que se teria desenvolvido. Há com efeito na literatura uma aspiração nacional, definida claramente a partir da Independência e precedendo o movimento romântico.[...] [...] Os românticos - Bernardo, Alencar, Taunay, Távora - tomaram a região como quadro regional e social em que se passavam atos e sentimentos sobre os quais incidia a atenção do ficcionista (CANDIDO, 1997, p. 15; p. 192)
} 
A preocupação dos românticos, portanto, residia mais em apresentar a realidade local do país do que em compreendê-lo. Com essa mentalidade, os romancistas acabaram criando narrativas artificiais e superficiais, cujo único objetivo era vender o exótico e o pitoresco brasileiros. $O$ Gaúcho (1870), de José de Alencar, é a síntese dessas idéias, já que o autor escreveu o romance sem nunca antes ter pisado no Rio Grande do Sul.

Além disso, o uso da linguagem ora culta, no discurso do narrador, ora coloquial, no discurso das personagens, favorece ainda mais a alienação e a superficialidade do romance. Vale ressaltar que essa distinção de linguagem entre os discursos da narrativa reforça o preconceito e o desapreço, por parte dos autores, pelas variedades lingüísticas vigentes no interior do país, consideradas desprestigiadas.

No segundo momento da tradição regional, estão inseridas as obras conhecidas como "Romance de 30 e de 45". Caracterizando esse momento, Antonio Candido afirma:

\begin{abstract}
O fato mais saliente foi a voga do chamado 'romance do Nordeste', que transformou o regionalismo ao extirpar a visão paternalista e exótica, para lhe substituir uma posição crítica extremamente agressiva, não raro assumindo o ângulo do espoliado, ao mesmo tempo que alargava o ecúmeno literário por um acentuado realismo no uso do vocabulário e na escolha da situação (CANDIDO, 1987, p. 204)
\end{abstract}

A partir da afirmação do crítico, constatamos que os escritores deixaram de lado o projeto de construção de identidade do país para pisar em um terreno mais fértil e mais difícil: o da denúncia social, o que demonstra um início de tomada de consciência dos romancistas, com o intuito de fazer o público pensar. Nesse período, observamos também um outro dado novo: a inserção dos pobres nas narrativas, ocupando o papel de protagonistas. A respeito, Luís Bueno afirma:

\begin{abstract}
Como se sabe, esta vertente colaborou grandemente para que se ampliassem as possibilidades tanto temáticas, quanto da constituição de um novo tipo de protagonista para o romance brasileiro. A incorporação dos pobres pela ficção é um fenômeno bem visível nesse período. De elemento folclórico, distante do narrador até pela linguagem, como se vê na moda regionalista do início do século, o pobre, chamado agora de proletário, transforma-se em protagonista privilegiado nos romances de 30 , cujos narradores procuram atravessar o abismo que separa o intelectual das camadas mais baixas da população escrevendo uma linguagem mais próxima da fala (BUENO, 2001, p. 254)
\end{abstract}

Mas a questão lingüística ainda é problemática e o abismo entre o narrador intelectual e a personagem pobre persiste. Graciliano Ramos, em Vidas Secas, consegue resolver o problema, na medida em que vale-se da linguagem mais para determinar a atmosfera do texto e o drama da saga da família no sertão, do que necessariamente para narrar. Não há um envolvimento direto entre o narrador e as personagens e, por isso, o autor conseguiu com maestria tratar do preconceito em relação às camadas mais humildes da população, perdendo, assim, o superficialismo dos escritores da fase anterior. Bueno (2001), em relação à incorporação do "outro" ressalta: "Graciliano Ramos não precisava valorizá-lo conscientemente, porque a percepção de sua autonomia - e portanto de sua condição humana - já é também a demonstração de seu valor" (BUENO, 2001, p. 269). 
O derradeiro e, para essa análise, mais importante momento regionalista foi cunhado pelo crítico Antonio Candido:

\footnotetext{
Descartando o sentimentalismo e a retórica; nutrida de elementos não-realistas, como o absurdo, a magia das situações; ou as técnicas antinaturalistas, como o monólogo interior, a visão simultânea, o escorço, a elipse - ela implica não obstante em aproveitamento do que antes era a própria substância do nativismo, do exotismo e do documentário social. Isto levaria a propor a distinção de uma terceira fase, que se poderia (pensando em surrealismo, ou super-realismo) chamar de super-regionalista. Ela corresponde à consciência dilacerada do subdesenvolvimento e opera uma explosão do tipo de naturalismo que se baseia na referência a uma visão empírica do mundo; naturalismo que foi a tendência estética peculiar a uma época onde triunfava a mentalidade burguesa e correspondia à consolidação das nossas literaturas (CANDIDO, 1987, p. 161-162 - grifo do autor)
}

Como podemos observar, o regionalismo se transformou, os escritores já não se satisfaziam em retratar o exótico e pitoresco do país, era preciso ir mais fundo, inserir nas regiões descritas não só suas paisagens, mas também a cultura, o dialeto, os desejos e os anseios dos moradores dessas regiões. Cabe salientar que Simões Lopes Neto, ao nosso ver, embora temporalmente não localizado nesse período, foi o precursor do superregionalismo, considerando que ele antecipou o uso da linguagem coloquial na voz do narrador, não se preocupando com questões formais (acadêmicas), além de trabalhar temas humanos que dizem respeito a todos. Essa conscientização literária é seguida por Guimarães Rosa em seus contos e, principalmente, no seu maior trabalho, o romance Grande Sertão: Veredas (1956), que demonstra, mais uma vez, o salto de qualidade que o romance regional brasileiro obteve. Na esteira de Guimarães Rosa, Ribeiro foi buscar na cultura popular e na literatura oral elementos para constituir seu romance. Essa atitude apaga definitivamente as barreiras entre o erudito e o popular e entre o culto e o oral, aproximando códigos e elementos rechaçados pela maioria dos escritores anteriores. $\mathrm{O}$ super-regionalismo configurou-se, portanto, como um período de abertura da tradição literária a formas consideradas "impuras".

\section{AS MANIFESTAÇÕES DO POPULAR EM SARGENTO GETÚLIO}

Em Sargento Getúlio (1971), Ribeiro utiliza-se da temática e da linguagem regional para compor seu romance. Não há arficialismos, pois o linguajar do sertão é grafado tal qual é oralmente, e é imprescindível destacar que a linguagem assume uma função maior do que o simples fato de narrar, ela é responsável por transmitir o ritmo das reflexões e das ações da personagem principal. As regras de pontuação são abolidas e esta é feita conforme as situações e as emoções vividas pelo protagonista. $\mathrm{O}$ árduo caminho que a personagem percorre é mostrado sem retoques, sem cortes. O Sargento é um anti-herói que sofre, que ri, que pensa (grande parte do romance é composta por um monólogo interior), tornando a narrativa, assim, ainda mais original. O conflito psicológico-existencial que rege a narrativa é a ponte construída por Ribeiro entre o regional e o universal. 
A equação narrativa que João Ubaldo Ribeiro apresenta constitui-se na oposição entre o sertanejo que é padrão de referência; o guerreiro, um forte $e^{l}$, e o sertanejo apresentado por ele forte fisicamente, entretanto, psicologicamente fragilizado. Para resolver tal equação, nos apoiaremos em como o passado e a cultura desse povo influenciou o autor na construção da personagem e do romance num todo.

Algumas considerações acerca dos aspectos estruturais da obra são fundamentais para a absorção da complexidade do enredo. O narrador-protagonista, em primeira pessoa do presente, inicia a narrativa dialogando com o seu parceiro, Amaro, entretanto, esse diálogo toma a forma de um monólogo, visto que Amaro somente escuta, não participa. No desenvolver do romance, o foco narrativo mantém-se em primeira pessoa, mas o tempo verbal altera-se na medida em que o protagonista começa a contar histórias acontecidas anteriormente. Os fatos lembrados misturam-se as falas do presente. É fundamental ressaltar que a passagem de um tempo verbal para outro ocorre inesperadamente, gerando ao leitor mais desatento uma certa confusão. O discurso é praticamente indireto livre, até mesmo alguns diálogos acontecem sem nenhuma marca gráfica:

Vá desafastando, vá desafastando, vá desafastando, e passando pela revisão da porta [...] No meio daquele baba todo, o homem querendo fazer discurso. Que significa isso? Que significa isso? Que significa isso, sargento? Senhor desculpe, senhor vai com a gente mestre. ${ }^{2}$

Temos a sensação de que o autor utiliza esses recursos para causar uma proximidade da personagem principal com o leitor. $\mathrm{O}$ uso da primeira pessoa no discurso do narrador também demonstra o desejo de João Ubaldo Ribeiro inserir a personagem a realidade. A utilização do dialeto oral regional reforça essa hipótese, dado que ele é grafado tal qual é pronunciado, enquanto o uso peculiar da pontuação determina o ritmo das ações do protagonista.

Eu sou Getúlio Santos Bezerra e meu nome é um verso e meu avô era brabo e todo mundo na minha raça era brabo e minha mãe se chamava justa e era braba e no sertão daqui não tem ninguém mais brabo do que eu, todas as coisas eu sou melhor (p. 84)

Essas características inserem o romance na tradição literária nordestina, que tem como maior representante o cordel. Acredita-se que a literatura de cordel tenha surgido no Brasil a partir de influências trazidas pelos nossos colonizadores, que uniram-se, aqui, à tradição oral da população do Nordeste, tornando-se, portanto, uma característica dessa região.

No Nordeste [...], por condições sociais e culturais peculiares, foi possível o surgimento da literatura de cordel, da maneira como se tornou hoje em dia característica da própria fisionomia cultural da região. Fatores de formação social contribuíram para isso; a organização da sociedade patriarcal, o surgimento de

\footnotetext{
${ }^{1}$ Termo utilizado por Euclides da Cunha em Os Sertões.

${ }^{2}$ RIBEIRO, João Ubaldo. Sargento Getúlio. Rio de Janeiro: Nova Fronteira, 1971. p.17. A partir desta nota, todas as citações ao romance terão apenas a página referida no corpo do texto por serem provenientes da mesma edição.
} 
manifestações messiânicas, o aparecimento de bandos de cangaceiros ou bandidos, as secas periódicas provocando desequilíbrios econômicos e sociais, as lutas de família deram oportunidade, entre outros fatores, para que se verificasse o surgimento de grupos de cantadores como instrumento do pensamento coletivo, das manifestações da memória popular (DIEGUES JUNIOR apud GALVÃO, 2001, p. 31)

Portanto, a literatura de cordel, ou de folhetos, como também é conhecida, caracteriza-se pela forte presença da oralidade, porém, é necessariamente uma produção impressa, diferenciando-se, deste modo, das poesias dos cantadores e dos repentistas referidas na citação acima, que eram estritamente orais. Os fatos e as personagens históricos famosos são os temas preferidos dos cordelistas, que não raro fazem uma leitura bem peculiar desses acontecimentos dando-lhes caráter ora humorístico, satírico, jocoso; ora dramático. Antônio Conselheiro, Padre Cícero e Lampião figuram com frequiência nas páginas dos folhetos.

Em muitos outros aspectos a narrativa de Ribeiro aproxima-se do cordel. O elemento mítico-religioso, "expressado através de ações sobrenaturais (os processos de encantamento e desencantamento, a magia), da presença da morte, da força inevitável do destino (da sina, do acaso), da religiosidade cristã, está presente" (GALVÃO, 2001, p. 81).

Esse elemento é muito cotejado pelo autor, tanto que ele é abordado explicitamente, como no episódio do diabo Erundino, ou nas entrelinhas, como veremos no decorrer da análise. Nesse episódio, Getúlio compara o preso que está carregando com um diabo que apareceu para uma tia sua numa determinada ocasião. Em tal cena, conferimos dois aspectos culturais: o hábito tradicional de contar histórias e a manifestação de uma crença instituída no imaginário popular. É interessante notar a comicidade, não só do vocabulário utilizado, mas também do episódio propriamente dito, o que aproxima a obra ainda mais das produções de cordel.

Sabemos que a narrativa acontece no início da década de 1950, pois concorrem à presidência da República Cristiano Machado (PSD), Getúlio Vargas (PTB) e o Brigadeiro Eduardo Gomes (UDN). A política coronelista, embora enfraquecida, ainda era vigente e, portanto, o clero ainda mantinha relações com os chefes políticos. Também temos conhecimento de que o conflito que atormenta o Sargento é a impossibilidade de cumprir uma missão que lhe foi destinada, em função da contra-ordem recebida pelo chefe. Sendo assim, procurado pelas forças federais, Getúlio passa a esconder-se. Primeiramente, na fazenda de Nestor, onde foi surpreendido pelas forças federais, partindo, então, com o preso, para a casa do "Padre de Aço da Cara Vermelha". (p.61) O elemento mítico-sacral, nesse ponto da narrativa, manifesta-se pela religiosidade cristã, pois, logo que chegam à casa do Padre, são postos a rezar.

O padre é uma figura ambígua se olharmos para ele com olhos de cidadãos contemporâneos. Tal personagem, "criação magistral de João Ubaldo Ribeiro -, bondoso, mas impotente diante do abismo gerado pela defasagem histórica". (DACANAL, 1988, p. 97), ao mesmo tempo em que aconselha positivamente Getúlio, concorda com as brutalidades cometidas por ele. No trecho abaixo, um diálogo entre o padre e o Sargento, podemos observar o comportamento do primeiro: 
Porque esse caso já está com cheiro de podre, diz o padre, e eu nem sei se vosmecês das duas uma: ou dá um fim direto nesse cristão, louvado seja Nosso Senhor Jesus Cristo, para sempre seja louvado, ou então solta ele [...] Inda mais, diz o padre, que temos aqui trocidades, dentes arrancados, violências, e os tempos estão mudando e vosmecê cortou a cabeça dum tenente e não sei como é que isso vai ser, inda se fosse um cabo [...]. Mas mesmo nesse minuto se senta na marquesa e olha para lado do coisa e fica olhando mais e mais e aí se acalma.

- É isso mesmo. Tem muitas cabeças nesse mundo de meu Deus.

- O tenente me chamou de corno, seu padre. Era ele ou eu.

- É isso mesmo - diz o padre. - Devia ter cortado mesmo.

E se benzeu e disse que não precisava dizer aquilo (p. 82-83)

Então, primeiramente, o padre diz-se indignado com a violência exacerbada cometida pelo Sargento, mas parece-nos que, no caso do degolamento do tenente, não é o ato em si que impressiona o padre, mas o fato de ter sido cometido contra um superior de Getúlio! ("inda se fosse um cabo"). No decorrer do diálogo, concorda com tal atitude e depois arrepende-se de ter falado, dando a entender que até poderia pensar assim, mas não deveria expressar. E então surge a pergunta de um leitor do século XXI, oriundo de uma sociedade judaico-cristã: pode um padre compactuar com tamanha violência?

Bem, o que não podemos esquecer é que estamos tratando de um universo que é terra de ninguém e que tem suas próprias regras: o sertão. Se o Sargento age em desconformidade com a sociedade vigente da época, é necessário levar em conta que ele carrega nas costas um passado histórico marcado pela opressão, pela discriminação e, principalmente, pela resistência, seja manifestada através das lutas entre classes (Revolta do Reino da Pedra, Guerra de Canudos, dentre outras), seja na figura de Lampião. Portanto, o uso da força física e da violência é intrínseco não só à realidade social desse indivíduo, mas também à sua mentalidade, influenciada pela História. Gostaríamos de lembrar que há, no romance, referências à Guerra de Canudos feitas à moda sertaneja: em forma de versos, cantados por Amaro, ridicularizando as forças oficias, certamente, com o intuito de frisar o caráter batalhador do povo nordestino.

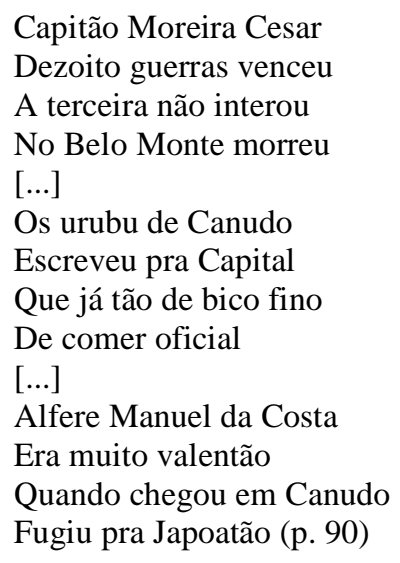

Getúlio tem Lampião como um ídolo. Inúmeras vezes refere-se ao cangaceiro de modo elogioso, como na cena em que Lampião amarra a mulher de um juiz, nua, a um poste. O protagonista traz consigo resquícios desse sistema de sobrevivência, ainda 
valendo-se da violência para impor medo e respeito. Algumas cenas do romance, como o assassinato de sua mulher que estava grávida e a degola do tenente, equiparam as atitudes do Sargento às dos cangaceiros.

Getúlio não aceita o cancelamento da missão. É necessário lembrar que ela tem de ser anulada, porque Acrísio, o "chefe" do Sargento, está sendo pressionado pelo governo federal. É evidente que Acrísio joga nos dois times, pois diz aos jornais que não mandou prender ninguém, enquanto manda Getúlio esconder-se na fazenda de Nestor. Contudo, quando as forças federais chegam à Aracaju, informa o paradeiro do preso e, conseqüentemente, de Getúlio. A partir desse episódio, começa a saga de resistência do protagonista. Ele não entende por que não pode continuar a missão e, vendo-se encurralado, desabafa:

Eu fico pensando assim aqui de preto se eu fosse para o cangaço, se tivesse cangaço [...]. Se tivesse eu ia para o cangaço, com um chapéu de estrelas prateadas e ia me chamar Dragão Manjaléu e ia falar pouco e fazer muito [...]. Eu ia ser o maior cangaceiro do Brasil, o maior piloto de jagunço do Brasil. E se não me chamasse de Sargento, me chamasse de capitão (p. 115; 122)

Observamos, portanto, que a personagem tinha condições físicas para fugir, afinal, teria forças para virar cangaceiro, caso o cangaço ainda existisse, entretanto, como não existe mais, fugir simplesmente é inaceitável, pois não cumprir a missão significaria tomar uma atitude de covarde "e se me perguntasse quer viver uma vida comprida amofinado ou quer viver uma vida curta de macho, o que era que eu respondia? [...] quero viver uma vida curta de macho sendo eu e mais eu". (p. 153) Assim, a impossibilidade de cumprir o que lhe foi destinado e a inaceitação da possibilidade de desistir deixam para o protagonista uma única saída: a morte.

Segundo Galvão (2001), o elemento mítico-religioso, muitas vezes, é o meio que possibilita que o herói cumpra sua sina. Em Sargento Getúlio, a morte é quem cumpre esse papel, sendo um elemento essencial no romance, visto que é a partir da morte de Amaro e de Luzinete que o protagonista começa a ter consciência da sua impotência diante da situação, sendo conduzido, então, inevitavelmente, para o cumprimento do seu destino, isto é, o desfecho da narrativa. No trecho abaixo, presenciamos o Sargento narrando a sua própria morte:

\footnotetext{
eu vou morrer e nunca vou morrer eu nunca vou morrer Amaro eu nunca vou morrer um aboio e uma vida Amaro aaaaaaaaaaaaaahhh eeeeeeeeeeh aê aê aê aê aê ecô ecô aê aê aê aê eu nunca vou morrer Amaro e Luzi netena lua essas balas é como meu dedo longe e o lhelá Ara eu vejocaju e a água cor redonde vagar e sal gadela éboa num cavoumor rernum caesoueu, ai um boi de barro, aiumboi aiumboide barroaê aê aê aiumgara jauchei de barro e vidaeu sou eu e vou e quem foi ai mi nhalaran jeiramur chaai ei eu vou e cumpro e faço e (p. 157)
}

Nesse fragmento, também podemos observar que algumas especificidades do popular são apontadas, como, por exemplo, o localismo dos termos, a oralidade utilizada de forma exacerbada, a irregularidade da pontuação e a referência a aspectos culturais. A aglutinação desses fatores de forma desordenada reflete a confusão mental, o devaneio da personagem diante do seu final trágico. 
Percebemos que à morte é também atribuída uma outra função: a transformação do Sargento em mito, em lenda, segundo o seu próprio desejo:

sendo eu mais eu e respeitado nesse mundo e quando eu morrer se alembrem de mim assim: morreu o Dragão. Que trouxe mortandade para os inimigos, que não traiu nem amunhecou, que não teve melhor do que ele e que sangrou quem quis sangrar. Agora eu sei quem sou (p. 153)

É ela que permite que Getúlio, assim como Lampião, seja lembrado e relembrado por todos, através da oralidade, sobrevivendo à passagem do tempo e perpetuando-se no inconsciente das pessoas. É necessário chamar atenção para um dado do romance: como pode o Sargento ser o narrador se ele morre no final da história? Seria esse um elemento mítico-religioso velado? De qualquer forma, trata-se de um elemento fantástico aceito com naturalidade no imaginário popular.

Getúlio tinha consciência de que a política e o mundo estavam mudando "A política está mudando, eu disse, está ficando uma política maricona".(p. 56), "Não gosto que o mundo mude, me dá uma agonia, fico sem saber o que fazer".(p. 94), mas não acreditamos que seja somente a transição do mundo primitivo para o mundo urbanizado que condena a personagem à morte. A impossibilidade de adequação do Sargento na sociedade que está se anunciando não diz respeito somente à sua defasagem histórica, mas sim à sua fragilidade psicológica. Supomos que, a partir dessa reflexão, conseguiremos resolver a equação Ribeiriana acerca do romance. Basta pensarmos, novamente, nos cangaceiros. Queiroz (1997) conta-nos que, após a morte de Lampião, os cangaceiros independentes sobreviventes, depois de cumprirem pena, conseguiram reintegrar-se à sociedade, deixando de existir como tipo social forte. Entretanto, essa possibilidade era inviável para o Sargento, pois render-se implicaria um drama de consciência que o protagonista jamais conseguiria superar. E é esse o fator que condena a personagem e permite que João Ubaldo Ribeiro crie e recrie o sertanejo, possibilitando que esse tipo social saia da realidade e entre na arte.

Esse conflito psicológico é a manifestação do erudito na narrativa. Ribeiro consegue administrar muito bem as duas vias do romance, mesclando erudito e popular, não permitindo uma leitura unilateral. $\mathrm{O}$ escritor sergipano incorporou o pobre no primeiro plano da narrativa e abordou o banditismo do sertão sem atribuir à personagem principal um caráter pitoresco ou caricato (e por que não preconceituoso?), como aconteceu com frequiência nos romances regionalistas brasileiros. Também é importante lembrar que o autor resolveu o impasse linguístico sofrido pelos regionalistas anteriores sem banalizar o dialeto sertanejo, e isso só foi possível porque

Só há uma relação fecunda entre o artista e a vida popular: a relação amorosa. Sem um enraizamento profundo, sem uma empatia sincera e prolongada, o escritor, homem de cultura universitária, e pertencente à linguagem redutora dominante, se enredará nas malhas do preconceito, ou mitizará irracionalmente tudo que lhe pareça popular, ou ainda projetará pesadamente as sua próprias angústias e inibições na cultura do outro, ou, enfim, interpretará de modo fatalmente etnocêntrico e colonizador os modos de viver do primitivo, do rústico, do suburbano (BOSI apud PINHEIRO; LÚCIO, 2001, p. 79) 
Portanto, foi a identificação do escritor com o popular que deu à sua personagem o título de herói e não de bandido. O Sargento é perdoado pela transgressão das leis e dos princípios éticos por tornar-se representante das necessidades e dos valores coletivos, sejam eles sociais ou psicológicos.

Somente o conhecimento prévio da árdua história do povo nordestino, diluído em pouco de sensibilidade, é capaz de compor um homem que é vítima e culpado ao mesmo tempo.

Acreditamos, pois, que fazendo esse cotejo entre uma obra canônica, de valor e de qualidade esteticamente reconhecidos pela tradição literária, e a literatura oral e popular estamos abrindo uma possibilidade de um novo caminho na história literária brasileira. Não queremos que essas produções sejam aceitas como obras-primas literárias, mas desejamos, apenas, que sejam reconhecidas pela tradição e avaliadas com critérios específicos e não com os ditados pela crítica tradicional.

\section{REFERÊNCIAS}

BOSI, Alfredo. Literatura e Resistência. São Paulo: Companhia das Letras, 2002.

BUENO, Luis. Guimarães, Clarice e antes. In: Teresa - Revista de literatura brasileira II. São Paulo: Editora 34, 2001.

CANDIDO, Antonio. A educação pela noite e outros ensaios. São Paulo: Ática, 1987.

- Formação da Literatura Brasileira: momentos decisivos. Belo Horizonte / Rio de Janeiro: Itatiaia, 1997. 2 vol.

DACANAL, José Hildebrando. Nova narrativa épica no Brasil. Porto Alegre: Mercado Aberto, 1988.

GALVÃO, Ana Maria Oliveira. Cordel: leitores e ouvintes. Belo Horizonte: Autêntica, 2001.

PINHEIRO, Hélder; LÚCIO, Ana Cristina Marinho. Cordel na sala de aula. São Paulo: Duas Cidades, 2001.

QUEIROZ, Maria Isaura Pereira de. Os cangaceiros. São Paulo: Duas Cidades, 1997.

RIBEIRO, João Ubaldo. Sargento Getúlio. Rio de Janeiro: Nova Fronteira, 1971. 